\title{
Studies of acute and subchronic systemic toxicity associated with a copper/low-density polyethylene nanocomposite intrauterine device
}

This article was published in the following Dove Press journal:

International Journal of Nanomedicine

\section{Li-Xia Hu, ${ }^{1, *}$ Shi-Fu Hu, ${ }^{2, *}$ Meng Rao, ${ }^{2,3}$ Jing Yang, ${ }^{2,4}$ Hui Lei, ${ }^{2,5}$ Zhuo Duan, ${ }^{6}$ Wei Xia, ${ }^{2,7}$ Changhong $\mathrm{Zhu}^{2,7}$}

'Department of Histology and Embryology, Preclinical Medicine College, Xinxiang Medical University, Xinxiang, Henan, People's Republic of China; ${ }^{2}$ Family Planning Research Institute, Tongji Medical College, Huazhong University of Science and Technology, Wuhan, Hubei, People's Republic of China; ${ }^{3}$ Department of Reproduction and Genetics, the First Affiliated Hospital of Kunming Medical University, Kunming, Yunnan, People's Republic of China; ${ }^{4}$ Department of Gynecology, The First Affiliated Hospital of Zhengzhou University, Zhengzhou, Henan, People's Republic of China; ${ }^{5}$ Department of Gynaecology and Obstetrics, Taikang Tongji Hospital, Wuhan, Hubei, People's Republic of China;

${ }^{6}$ Dayu Medical Devices Co., Ltd., Jingzhou, Hubei, People's Republic of China; ${ }^{7}$ Reproductive Medicine Center, Tongji Medical College, Huazhong University of Science and Technology, Wuhan, Hubei, People's Republic of China

*These authors contributed equally to this work

Correspondence: Wei Xia; Changhong Zhu

Family Planning Research Institute, Tongji Medical College, Huazhong University of Science and Technology, 13 Hangkong Road, Wuhan 430030, Hubei, People's Republic of China

Tel +86278369265I

Fax +86 2783692651

Email tjxiawei@hust.edu.cn; reprodcentre@।63.com
Introduction: The physiologic safety of devices and materials intended for clinical implantation should be evaluated. This study, a logical extension of our previous work, aimed to investigate the safety of a novel contraceptive device, the copper/low-density polyethylene nanocomposite intrauterine device (nano-Cu/LDPE IUD), through studies of its potential toxicity after acute and subchronic administration in mice and rats.

Methods: For the acute toxicity study, single $50 \mathrm{~mL} / \mathrm{kg}$ doses of nano-Cu/LDPE IUD extracts were administered to mice via intravenous or intraperitoneal injection. General behavioral adverse effects, mortality, and body weights were evaluated for up to 72 hours. In the 13-week subchronic toxicity study, the nano-Cu/LDPE composite with 10-fold higher than the standard clinical dose was implanted subcutaneously into the dorsal skin of Wistar rats. The control group underwent a sham procedure without material insertion.

Results: During all acute study observation times, the biologic reactions of the mice in the nano- $\mathrm{Cu} / \mathrm{LDPE}$ group did not differ from those observed in the control group. The groups did not differ statistically in terms of body weight gain, and no macroscopic changes were observed in any organs. In the subchronic study, no clinical signs of toxicity or mortality were observed in either the nano- $\mathrm{Cu} / \mathrm{LDPE}$ or control group during the 13 -week period. The nano-Cu/LDPE composite did not cause any alterations in body weight, food consumption, hematologic and biochemical parameters, or organ weight relative to the control for any observed sample group. Histopathologic examinations of the organs revealed normal architecture, indicating that the inserted material did not cause morphologic disturbances in the rats.

Conclusion: Overall, the results indicate that the nano- $\mathrm{Cu} / \mathrm{LDPE}$ IUD did not induce systemic toxicity under experimental conditions of the recommended standard practices, suggesting that the novel material IUD is safe and feasible for future contraceptive applications.

Keywords: intrauterine device, copper/low-density polyethylene nanocomposite intrauterine device, acute toxicity, subchronic toxicity

\section{Introduction}

Since the beginning of the modern era of intrauterine contraception in 1959, intrauterine devices (IUDs) have become the world's most prevalent reversible contraceptive method, with approximately 175 million current users. ${ }^{1}$ Of these, nonhormonal IUDs have become the most widely used. IUDs can be divided into two groups based on the contraceptive mechanism: inert IUDs and active IUDs (Figure 1). ${ }^{2}$ Inert IUDs have been discontinued because of their poor contraceptive effects. Active IUDs mainly comprise copper IUDs and hormonal IUDs.

Copper-containing intrauterine devices (Cu-IUDs), which are safe, economical, long-lasting and effective, are increasingly used for population control worldwide. ${ }^{3-5}$ 


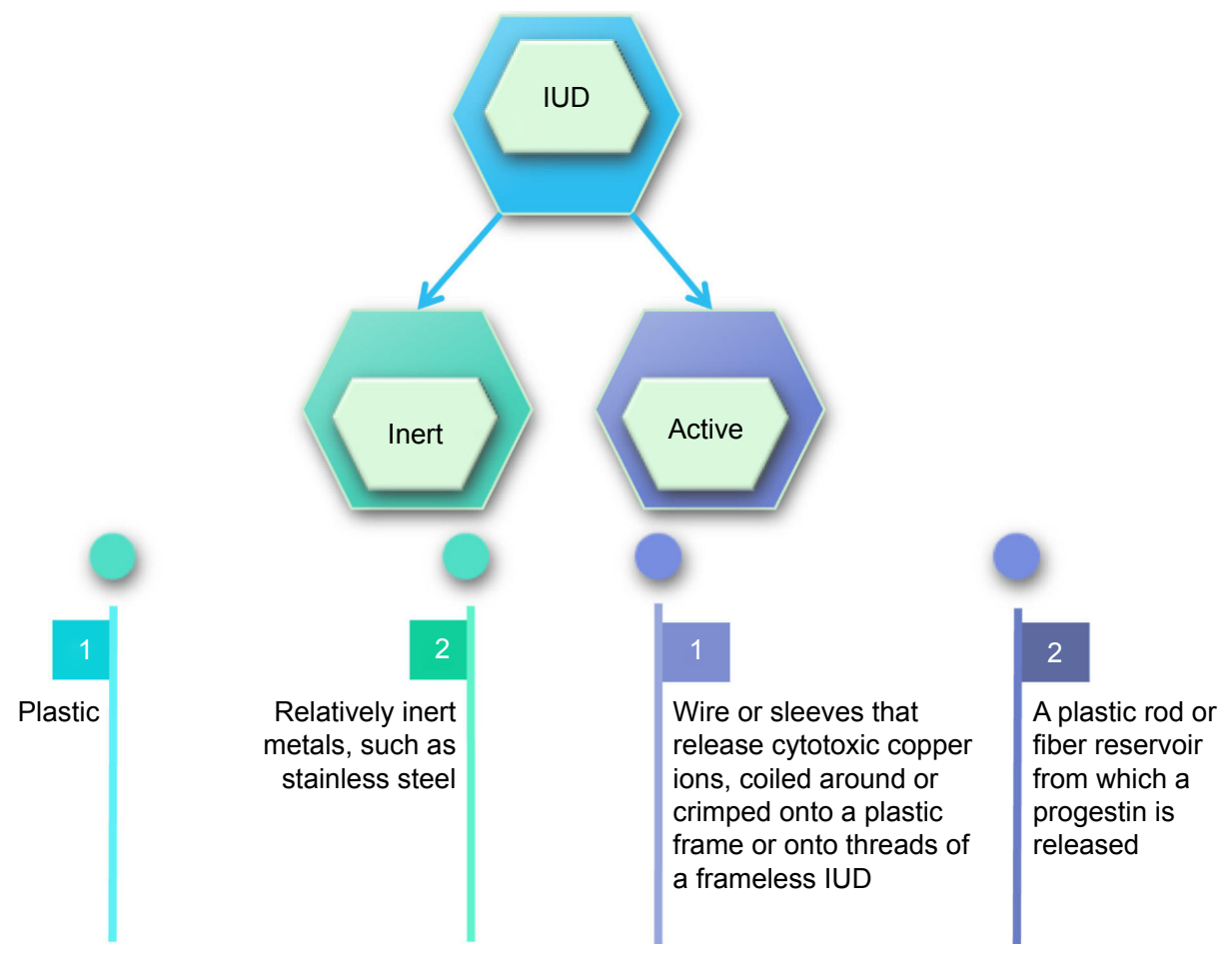

Figure I Types of IUDs.

Abbreviation: IUD, intrauterine device.

The enhanced contraceptive abilities of these devices are commonly attributed to their spermicidal activity; specifically, the activities of spermatozoa are inhibited by cupric ion biotoxicity. Additionally, $\mathrm{Cu}-\mathrm{IUDs}$ alter endometrial cell metabolism and biochemistry to inhibit embryo implantation after fertilization. ${ }^{6}$ Despite satisfactory contraceptive efficacy and very wide utilization, the clinical use of existing $\mathrm{Cu}$-IUDs is complicated by persistent side effects, including irregular and heavy bleeding, spotting, and pelvic pain. ${ }^{7}$ These side effects are most likely related to the burst release of cupric ions during the first few months of use. Therefore, controlling the process of cupric ion release and thus preventing such a burst initially after insertion should be considered to maximize contraceptive efficacy and minimize adverse effects. ${ }^{8}$

Recent decades have seen rapid advances in nanotechnology in many scientific fields (Figure 2). The characteristics of nanomaterials have contributed to notable biomedical achievements. In our previous studies, our research used nanotechnology in an attempt to decrease the side effects caused by $\mathrm{Cu}-\mathrm{IUDs}$ and invented a new type of copper/lowdensity polyethylene nanocomposite IUD (nano-Cu/LDPE IUD, Patent No ZL200610124658.9). Details of the preparation of this IUD have been described elsewhere. ${ }^{9-11}$ Briefly, the mechanical properties, corrosion behavior, and prospective life-span of the nano-Cu/LDPE IUD were superior to those of an existing Cu-IUD. ${ }^{11,12}$ Additionally, experiments to determine the contraceptive effectiveness, side effects, and safety of the nano-Cu IUD in rats, mice, rabbits, and rhesus monkeys demonstrated a high level of efficacy with low side effects and relative safety. ${ }^{8,13-17}$ In summary, previous studies of this novel composite IUD material indicate that it can greatly improve the performance of IUDs.

In recent years, biologic evaluations of biomaterials and medical devices have become increasingly globally standardized concurrent with the publication of the International Organization for Standardization (ISO) 10993 standard for biomaterial and medical device testing. As the nano-Cu/LDPE IUD is a novel substitute and implanted medical device, it is necessary to evaluate its safety through experimental protocols conducted according to regulatory standards. The results from previous biologic evaluations (cytotoxicity, skin irritation and sensitization, and implantation) indicate that the novel nano-Cu/LDPE IUD was highly likely to be histocompatible. ${ }^{18}$ However, systematic research regarding the possible toxicity of the nano-Cu/LDPE IUD has not yet been conducted.

The present study aimed to evaluate the systemic toxicity of this novel nano-Cu/LDPE IUD. Systemic toxicity is a potential adverse effect of medical devices. ${ }^{19}$ Generalized effects, as well as organ and organ system effects, can result from the absorption, distribution, and metabolism of device 


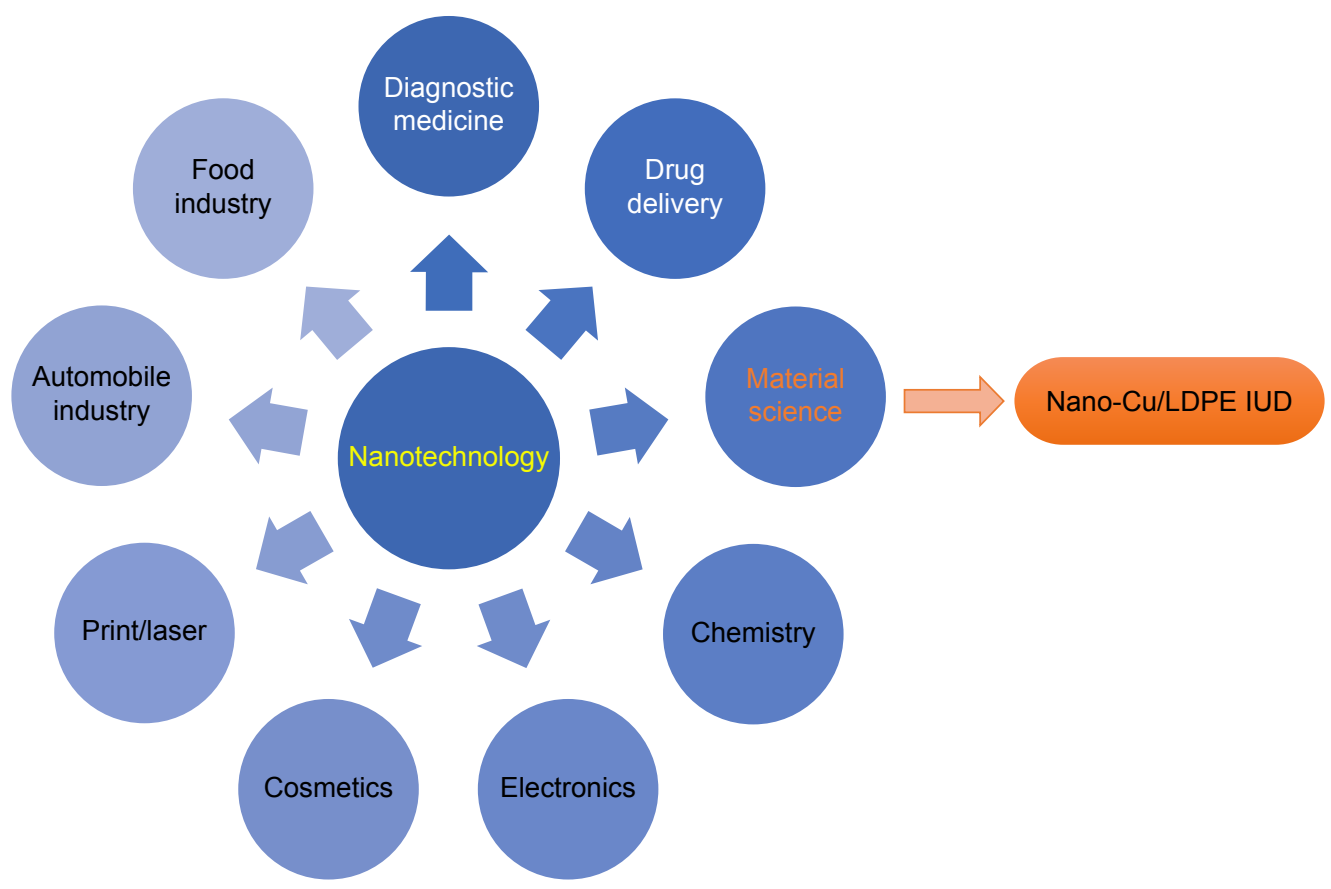

Figure 2 Application of nanotechnology.

Abbreviation: Cu-LDPE IUD, copper/low-density polyethylene nanocomposite intrauterine device.

leachates or materials to parts of the body with which they are not in direct contact. Therefore, toxicologic evaluations are performed in animal models to determine the safety of drugs and implantable medical products for human use. The present study, in which the potential toxicity of the novel nano- $\mathrm{Cu} /$ LDPE IUD was evaluated after acute and subchronic systemic assays, was conducted as part of an investigation to evaluate the safety of this device. The results may help us to determine whether the nanocomposite IUD meets the safety standards for implantable medical devices.

\section{Materials and methods Experimental animals}

Sexually mature Kunming mice (body weight: 17-23 g; SPF grade, Certificate No 0013938) and Wistar rats (body weight: 180-240 g; SPF grade, Certificate No 0013936) were obtained from the Experimental Animal Center of Shandong Lukang Pharmaceutical Co., Ltd. and acclimatized in the laboratory for 1 week before starting the experiment. The animals were individually housed and maintained under standard conditions (12-hour light/dark cycle, $22^{\circ} \mathrm{C} \pm 1{ }^{\circ} \mathrm{C}$, $50 \%-60 \%$ relative humidity) and provided a conventional laboratory diet and unrestricted supply of drinking water. All animal experiments were conducted in compliance with the local Ethics Committee and were approved by the Institutional Review Board at Shandong Quality Inspection
Center for Medical Devices. Systemic toxicity studies were performed in accordance with the ISO 10993-11 standard. This section of ISO 10993 specifies the requirements for and gives guidance on the procedures to be followed when evaluating the potential for medical device materials to cause adverse systemic reactions. ${ }^{19}$

\section{Materials}

The nano- $\mathrm{Cu} / \mathrm{LDPE}$ IUDs were provided by the Department of Materials Science and Engineering of Huazhong University of Science and Technology. The nanosized copper particles were generated using our own patented techniques (ie, hybrid induction and laser heating evaporation condensation method) and had a mean diameter of approximately $50 \mathrm{~nm}$ and purity $>99.9 \%$. The process used to prepare the nano- $\mathrm{Cu} / \mathrm{LDPE}$ IUD was introduced in our previous work (Figure 3). ${ }^{8}$ The nano-Cu/LDPE IUD comprises a pair of symmetrical transverse arms with a total length of $28 \mathrm{~mm}$ and a longitudinal stem with a total height of $30 \mathrm{~mm}$. Both the transverse arms and the longitudinal stem have a diameter of $2.0 \mathrm{~mm}$. The preparation of reference materials for this test was based on the standard ISO 10993-12. ${ }^{20}$

\section{Acute systemic toxicity}

Twenty mice were used in the evaluation of extracts from the nano- $\mathrm{Cu} / \mathrm{LDPE}$ IUDs administered via two different injection 


\section{LDPE powders + copper nanoparticles}

\begin{tabular}{l|l}
10 minutes & $\begin{array}{l}\text { Mixing in a } \\
\text { tumble mixer }\end{array}$ \\
Homogeneous \\
mixtures
\end{tabular}

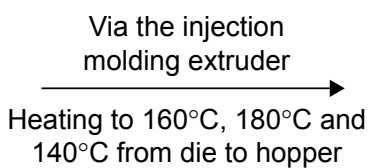

Via the injection

\begin{tabular}{l}
$140^{\circ} \mathrm{C}$ from die to hopper \\
\hline
\end{tabular}

\section{The nano-Cu/LDPE IUD}

Figure 3 The flow chart of the nano-Cu/LDPE IUD.

Abbreviation: Cu/LDPE IUD, copper/low-density polyethylene nanocomposite intrauterine device.

procedures (intravenous and intraperitoneal). Extracts prepared in a $0.9 \%$ sodium chloride solution and cottonseed oil were used for intravenous and intraperitoneal injection, respectively. The material extracts were prepared at a ratio of $1.25 \mathrm{~cm}^{2}$ of sample material per $1 \mathrm{~mL}$ of extract vehicle and were soaked for 24 hours at $37^{\circ} \mathrm{C}$. Ten mice were used per type of injection: five for the nano-Cu/LDPE group and five for the control group. Mice in the nano-Cu/LDPE group were injected with the material extracts at a dose of $50 \mathrm{~mL} / \mathrm{kg}$ body weight. Mice in the control group were injected with the same volume of blank extract vehicle. All tested animals were observed at 4, 24, 48, and 72 hours after injection, and symptoms of slight, moderate, or marked toxicity and death were recorded. The animals' body weights were also measured and recorded. During the observation period, if none of the animals in the nano-Cu/LDPE group exhibited significantly greater biologic reactivity than the animals in the control group, the sample would be considered to meet the requirements of this assay.

\section{Subchronic toxicity}

Upon initiating the experiment, 20 Wistar rats were randomly allocated to two groups: the nano-Cu/LDPE group ( $\mathrm{n}=10$, five males and five females) and sham-operated control group $(\mathrm{n}=10$, five males and five females). Group allocation was based on the body weights measured immediately before the experiment. Rats in the nano- $\mathrm{Cu} / \mathrm{LDPE}$ group were anesthetized with $10 \%$ chloral hydrate $(3 \mathrm{mg} / \mathrm{kg}$ via intraperitoneal injection). The $12.6 \mathrm{~mm}$ length of nano-Cu/LDPE composite material, equivalent to 10 -fold the human dose, was inserted subcutaneously into the dorsal skin. Rats in the control group underwent the same procedure without subcutaneous dorsal material insertion. Each rat was treated for 13 weeks.

\section{Clinical observations, body weight, and food consumption}

All animals were observed twice daily for clinical signs of toxicity and the clinical conditions were recorded. The observed signs included but were not limited to changes in skin, fur, eyes, and mucous membranes; occurrence of secretions and excretions and autonomic activity (eg, lacrimation, pupil size, piloerection, and unusual respiratory pattern). Changes in gait, posture, and responses to handling, as well as the presence of clonic or tonic movements, stereotypy, or bizarre behavior (eg, self-mutilation, walking backwards) were also recorded. The mean weekly body weight and food consumption were calculated for each rat throughout the test period.

\section{Urinalysis, hematology, and clinical biochemistry}

On the 89th day, each rat was placed in a metabolism cage for 24 hours for urine collection. The urine color was observed and the volume was recorded. The following parameters were analyzed using the Urine Test Strip Analyzer (CombiScan 500, Analyticon Biotechnologies AG, Lichtenfels, Germany): pH, specific gravity, nitrite, glucose (GLU), ketones, urobilinogen, and bilirubin. Blood samples were collected on the 91st day after an overnight fast. The following hematology assessments were conducted using an automated hematology analyzer (MEK-6318, Nihon Kohden, Tokyo, Japan): white blood cell count, red blood cell count, hemoglobin concentration, hematocrit, percent of neutrophilic granulocytes, percent of lymphocytes, percent of monocytes, and platelet count. The prothrombin time and activated partial thromboplastin time for blood coagulation were analyzed using a blood coagulation analyzer (CA-530, Sysmex, Kobe, Japan). Serum biochemical parameters, including alanine aminotransferase, total protein, albumin, total bilirubin, aspartate aminotransferase, total cholesterol, blood urea nitrogen, creatinine, GLU, sodium $(\mathrm{Na})$, potassium $(\mathrm{K})$, and chloride $(\mathrm{Cl})$, were evaluated using an automated biochemical analyzer (7020, Hitachi, Tokyo, Japan).

\section{Pathology}

All animals were necropsied, and descriptions of all macroscopic abnormalities were recorded at the scheduled 
termination. After removing peripheral fat, the following organs from each rat were weighed: brain, heart, thymus, thyroid, liver, lung, spleen, intestine, pancreas, kidney (left, right), adrenal gland (left, right), testis (left, right), epididymis (left, right), ovaries (left, right), and uterus. Relative organ weights were calculated according to the formula: Relative organ weight $(\%)=$ organ wt $(g) /$ body weight $(g) \times 100$. The peripheral oral cavity, cranial cavity, and all tissues and organs in the thoracic and abdominal cavity were examined visually for any abnormalities, which were recorded. All of the above-mentioned collected organs and tissues were fixed in $10 \%$ neutral buffered formalin, routinely processed, embedded in paraffin, sectioned at a thickness of 3-5 $\mu \mathrm{m}$, and stained with H\&E for microscopic examination. Tissue sections were observed using an optical microscope (Olympus, Tokyo, Japan).

\section{Statistical analysis}

All data are presented as means \pm SD. Body weights, hematology and serum biochemistry parameters, and relative organ weights were compared between the nano- $\mathrm{Cu} / \mathrm{LDPE}$ and control groups using the independent-samples $t$-test and SPSS 20 statistical software (SPSS Inc., Chicago, IL, USA). Male and female rats were evaluated separately. A $P$-value of $<0.05$ was considered statistically significant.

\section{Results}

\section{Acute toxicity}

During all observation times, no differences in biologic reactions were observed between mice in the nano- $\mathrm{Cu} / \mathrm{LDPE}$ group and those in the control group. No other abnormal behaviors or deaths were observed. The two groups did not differ statistically in terms of body weight gain $(P>0.05)$ (Table 1$)$.

Table I Body weight changes of mice in acute toxicity study (intravenous injection) (A) and (intraperitoneal injection) (B)

\begin{tabular}{llll}
\hline $\mathbf{A}$ & & & \\
\hline Group & $\mathbf{n}$ & Body weight $\mathbf{( g )}$ & \\
\cline { 3 - 4 } & & Before testing & $\mathbf{7 2}$ hours \\
\hline Nano-Cu/LDPE & 5 & $18.0 \pm 1.00$ & $21.8 \pm 1.64$ \\
Control & 5 & $18.2 \pm 0.84$ & $23.4 \pm 0.55$ \\
\hline B & & & \\
\hline Group & $\mathbf{n}$ & Body weight (g) & \\
\cline { 2 - 4 } & & Before testing & $\mathbf{7 2}$ hours \\
\hline Nano-Cu/LDPE & 5 & $17.8 \pm 0.84$ & $23.4 \pm 0.89$ \\
Control & 5 & $18.4 \pm 0.89$ & $22.6 \pm 1.34$ \\
\hline Note & &
\end{tabular}

Note: Values expressed as mean \pm SD.

Abbreviation: Cu/LDPE, copper/low-density polyethylene nanocomposite.
No alterations were observed in the macroscopic examination of the organs in all animals.

\section{Subchronic toxicity \\ Clinical observations, body weight, and food consumption}

No clinical signs of toxicity or mortality were observed in the nano- $\mathrm{Cu} / \mathrm{LDPE}$ and control groups during the 90-day study. The body weight and body weight gain for all groups in the 13-week trial were comparable to the control group values. No significant differences were noted in any male or female test groups relative to their corresponding control groups $(P>0.05)$. The body weight curves for male and female rats during the 13 -week period are shown in Figure 4. The mean weekly food consumption values for all groups of male and female rats were generally comparable with the control groups. Similarly, there were no statistical changes relative to the control in any observed sample group $(P>0.05)$ (Figure 5).

\section{Urinalysis, hematologic and biochemical analysis}

Semiquantitative urinary parameters, such as the urine volume, $\mathrm{pH}$, specific gravity, GLU, bilirubin, and urobilinogen, did not reveal any relevant changes at the end of the study (data not shown). Hematologic data are shown in Table 2. Blood coagulation tests and biochemical analysis data are shown in Tables 3 and 4. Compared to the control group, no statistically significant changes were detected in any parameters in the sample groups $(P>0.05)$.

\section{Pathology}

Relative organ weights are shown in Table 5. No significant differences were observed in the relative organ weights among animals of either sex after 13 weeks $(P>0.05)$. Gross necropsy revealed no abnormalities in rats from the nano- $\mathrm{Cu} /$ LDPE group. Finally, organs from animals in both groups were subjected to a microscopic examination. Histopathologic examinations of the brain, heart, and thymus (Figure 6), thyroid, liver, and lung (Figure 7), spleen, intestine, and pancreas (Figure 8), kidney and adrenal gland (Figure 9), and testis, epididymis, ovaries, and uterus (Figure 10) revealed normal architecture and indicated a lack of morphologic disturbances in the treated animals.

\section{Discussion}

The potential adverse effects of medical products on tissues and organs other than those in contact with the product are evaluated through systemic toxicity studies. Although the 

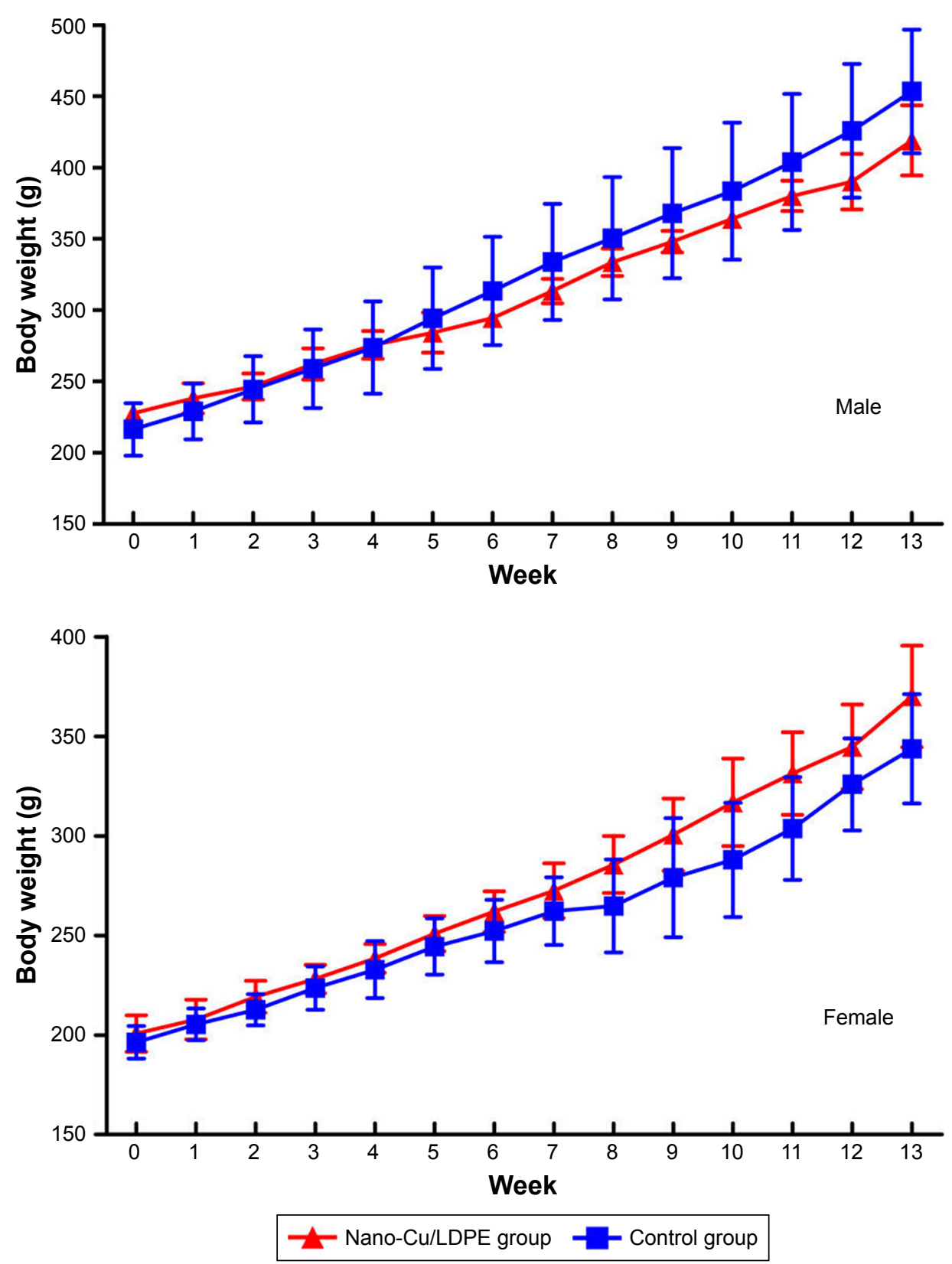

Figure 4 Body weight changes of male and female Wistar rats in subchronic study. Abbreviation: Cu/LDPE, copper/low-density polyethylene nanocomposite.

valid extrapolation of the results of these studies to humans is limited, the results can provide useful information regarding permissible human exposure. One section of ISO 10993 specifies the requirements for evaluating the potential for medical device materials to cause adverse systemic reactions and gives guidance on the procedures to be followed. ${ }^{19}$ The results of the present acute systemic toxicity experiment indicated that no mortality or evidence of any systemic toxicity was observed in any animal exposed to the extract liquids according to the recommendation specified by the systematic international guideline. The subchronic toxicity of
nano-Cu/LDPE IUD was assessed by implanting Wistar rats with an amount of nanocomposite equivalent to 10 -fold the human dose. No abnormal clinical observations, significant differences in serum chemistry or hematology parameters, or gross necropsy or histopathology abnormalities were noted in any of the animals. These results demonstrate that under experimental conditions and at the indicated doses, nano- $\mathrm{Cu} /$ LDPE IUD did not induce systemic toxicity in animals.

The contraceptive effect of a $\mathrm{Cu}-\mathrm{IUD}$ depends mainly on the release of cupric ions via the corrosion of copper. However, the excess release of cupric ions causes cytotoxicity 

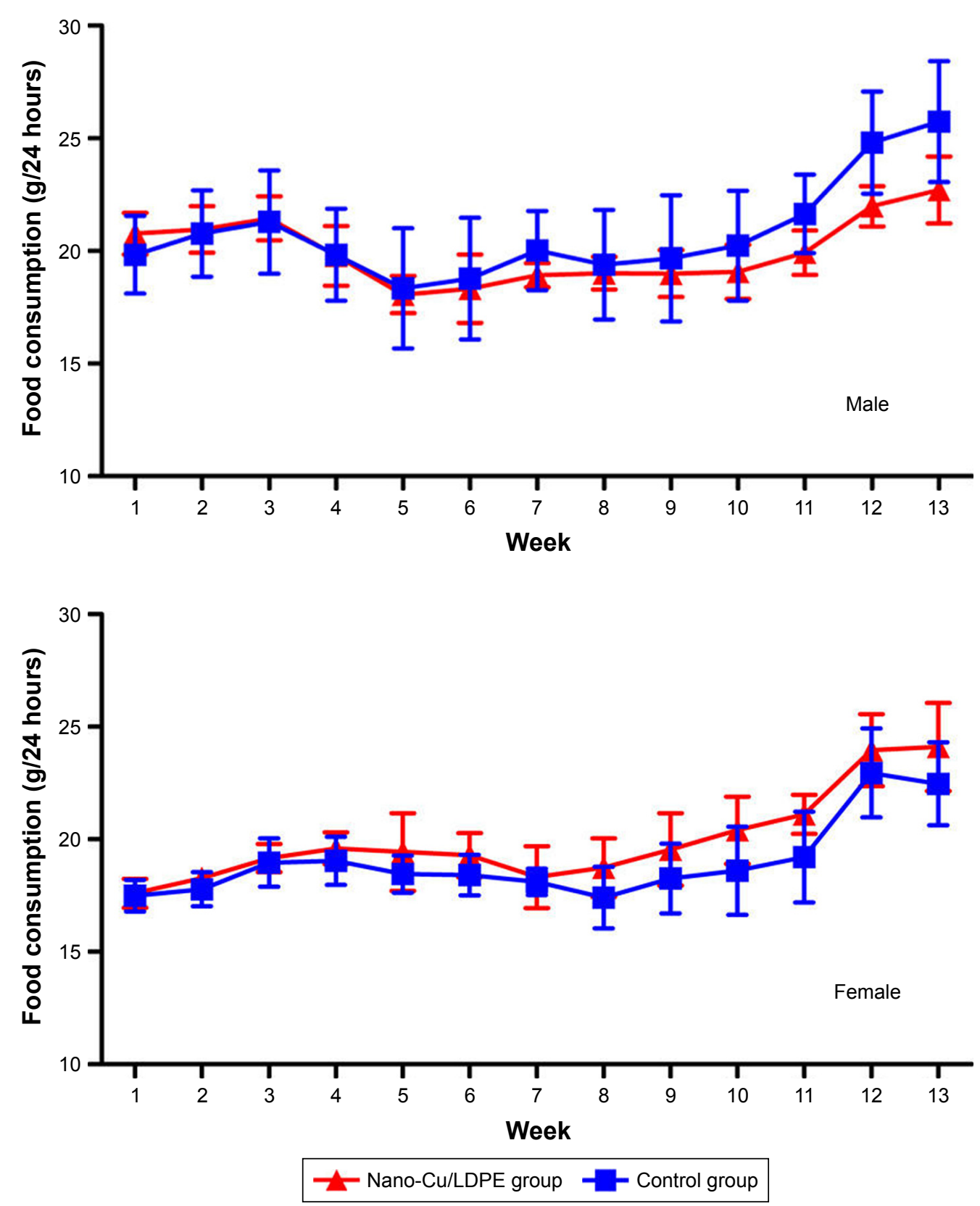

Figure 5 Food consumption changes of male and female Wistar rats in subchronic study. Abbreviation: Cu/LDPE, copper/low-density polyethylene nanocomposite.

Table 2 Hematology values of male rats $(\mathbf{A})$ and female rats $(\mathbf{B})$ in subchronic toxicity study

\begin{tabular}{|c|c|c|c|c|c|c|c|c|c|}
\hline \multicolumn{10}{|l|}{ A } \\
\hline Group & $\mathbf{n}$ & WBC $\left(\times 10^{9} / \mathrm{L}\right)$ & $\operatorname{RBC}\left(\times 10^{12} / L\right)$ & HGB (g/L) & НСТ (\%) & NEUT (\%) & LY (\%) & MO (\%) & PLT $\left(\times 10^{9} / \mathrm{L}\right)$ \\
\hline Nano-Cu/LDPE & 5 & $11.5 \pm 1.3$ & $7.7 \pm 0.9$ & $145.4 \pm 18.2$ & $40.9 \pm 4.5$ & $21.3 \pm 4.1$ & $66.0 \pm 2.8$ & $12.8 \pm 4.6$ & $435.2 \pm 7.6$ \\
\hline Control & 5 & $12.2 \pm 1.0$ & $7.5 \pm 0.5$ & $145.4 \pm 5.8$ & $41.9 \pm 2.3$ & $22.8 \pm 5.0$ & $61.7 \pm 3.6$ & $15.5 \pm 3.8$ & $442.6 \pm 18.6$ \\
\hline \multicolumn{10}{|l|}{ B } \\
\hline Group & $\mathbf{n}$ & WBC $\left(\times 10^{9} / L\right)$ & $\operatorname{RBC}\left(\times 10^{12} / L\right)$ & HGB (g/L) & НCT (\%) & NEUT (\%) & LY (\%) & MO (\%) & PLT $\left(\times 10^{9} / \mathrm{L}\right)$ \\
\hline Nano-Cu/LDPE & 5 & $9.2 \pm 0.3$ & $6.8 \pm 0.3$ & $142.6 \pm 7 . \mid$ & $42.2 \pm 2.7$ & $17.3 \pm 1.9$ & $69.7 \pm 1.9$ & $13.0 \pm 2.6$ & $416.2 \pm 20.4$ \\
\hline Control & 5 & $9.2 \pm 0.6$ & $7.1 \pm 0.4$ & $142.0 \pm 4.7$ & $41.0 \pm 1.9$ & $17.6 \pm 2.7$ & $68.0 \pm 2.2$ & $14.3 \pm 2.3$ & $425.0 \pm 8.5$ \\
\hline
\end{tabular}

Note: Values expressed as mean \pm SD.

Abbreviations: Cu/LDPE, copper/low-density polyethylene nanocomposite; HCT, hematocrit; HGB, hemoglobin concentration; LY, percent of lymphocyte; MO, percent of monocyte; NEUT, percent of neutrophilic granulocyte; PLT, platelet count; RBC, red blood cell count; WBC, white blood cell count. 
and increases the risk of adverse effects. ${ }^{21-23}$ The findings from several in vitro and in vivo assays provide evidence that cupric ions can interact directly with macromolecules to modify conformational structures, thus causing site-specific damage and indirectly catalyzing the formation of reactive oxygen species (ROS) via the Fenton/Haber-Weiss reaction to cause various cellular alterations. ${ }^{24,25}$ Previously, a study by Araya demonstrated that sperm motility decreased to nearly zero following exposure to a cupric ion concentration of approximately $8 \times 10^{-6} \mathrm{~mol} / \mathrm{L}(0.5 \mu \mathrm{g} / \mathrm{mL})$ for roughly 20 minutes. ${ }^{26}$ This suggests that a cupric ion concentration of $1.0 \mu \mathrm{g} / \mathrm{mL}$ is sufficient to inhibit the motility of human sperm in a simulated uterine solution, even if half of the released cupric ions were absorbed by the endometrium in vivo. Accordingly, $1.0 \mu \mathrm{g} / \mathrm{mL}$ can be considered the minimal cupric ion concentration required to ensure contraceptive efficacy of the IUD in clinical use. However, the cupric ion concentrations released from existing $\mathrm{Cu}$-IUDs in uterine fluid range from 3.9 to $19.1 \mu \mathrm{g} / \mathrm{mL}$, or much higher than the minimal concentration required to ensure contraceptive efficacy. ${ }^{6}$ Similar to the existing $\mathrm{Cu}-\mathrm{IUD}$, the novel nano-Cu/ LDPE IUD must release the minimum concentration of cupric ions to decrease the risk of adverse effects and ensure contraceptive efficacy.

Compared to conventional $\mathrm{Cu}-\mathrm{IUDs}$, nano- $\mathrm{Cu} / \mathrm{LDPE}$ IUDs have unique characteristics. First, the frame comprises an LDPE matrix, and copper nanoparticles are distributed uniformly in the composite. On one hand, LDPE exhibits remarkable biocompatibility with the human body and is widely used as an implantable material. On the other hand, the dispersal of nanoparticles throughout a polymer matrix has attracted considerable attention because of its superior properties relative to a neat polymer, including enhanced thermal stability, antimicrobial properties, and gas barrier properties. ${ }^{27-30}$ The rate of cupric ions' release from a

Table 3 Blood coagulation time of male rats $(\mathbf{A})$ and female rats (B) in subchronic toxicity study

\begin{tabular}{llll}
\hline $\mathbf{A}$ & & & \\
\hline Group & $\mathbf{n}$ & PT (seconds) & APTT (seconds) \\
\hline Nano-Cu/LDPE & 5 & $7.88 \pm 0.31$ & $21.34 \pm 0.86$ \\
Control & 5 & $7.98 \pm 0.18$ & $21.22 \pm 1.32$ \\
\hline B & & & \\
\hline Group & $\mathbf{n}$ & PT (seconds) & APTT (seconds) \\
\hline Nano-Cu/LDPE & 5 & $7.84 \pm 0.38$ & $21.60 \pm 1.17$ \\
Control & 5 & $7.80 \pm 0.20$ & $21.94 \pm 1.04$ \\
\hline
\end{tabular}

Note: Values expressed as mean \pm SD.

Abbreviations: APTT, activated partial thromboplastin time; Cu/LDPE, copper/ low-density polyethylene nanocomposite; PT, prothrombin time. nano- $\mathrm{Cu} / \mathrm{LDPE}$ IUD is determined by the internal structure and functional groups on the surface of the nano-Cu/LDPE IUD polymer matrix. The interior space provides an osmotic passage for cupric ions and corrosion mediators and can effectively control the corrosion rate by separating the copper nanoparticles within the matrix. This was confirmed by the prophase of study in which the material was shown to release cupric ions at a steady rate in simulated uterine solution, in contrast to the burst release of cupric ions from conventional $\mathrm{Cu}$-IUDs. ${ }^{31,32}$ Our previous research demonstrated that the average cupric ion concentrations released by the nano- $\mathrm{Cu} /$ LDPE IUD in simulated uterine solution are approximately $4.5482 \mu \mathrm{g} / \mathrm{mL}$ within 60 days and $4.4958 \mu \mathrm{g} / \mathrm{mL}$ within 120 days. ${ }^{11}$ In other words, the cupric ion concentration released by the nano-Cu/LDPE IUD in uterine fluid is apparently lower than that released by existing $\mathrm{Cu}$-IUDs. Furthermore, the results from a cytotoxicity assay indicated that the nano-Cu/LDPE IUD was nontoxic or mildly cytotoxic at all incubation periods and concentrations. Accordingly, these results met the requirements to ensure contraceptive efficacy.$^{18}$ In contrast to these findings, the currently available TCu220C IUD has more serious cytotoxic effects than those of the novel composite IUD. In this sense, the low level of cupric ions released by the nano-Cu/LDPE IUD induced little systemic toxicity in animals in the present study.

The nano-Cu/LDPE IUD also packages the copper nanoparticles in a framework composed of organic material, thus avoiding direct contact between metal and the endometrium. Here, cupric ions transformed by copper nanoparticles, rather than the nanoparticles themselves, act on the endometrium. The mechanism underlying the release of cupric ions from the nano-Cu/LDPE IUD can be explained as follows. ${ }^{9-11} 1$ ) The simulated uterine solution enters the nano- $\mathrm{Cu} / \mathrm{LDPE}$ composite via spaces in the sample. 2) The copper nanoparticles dispersed homogeneously in the LDPE matrix convert to $\mathrm{Cu}$ ions upon contact with the simulated uterine solution. 3) The concentration gradient of cupric ions from the inside to the outside of the sample allows the diffusion of cupric ions into the external solution. Cupric ions thus diffuse through the polymer matrix by traveling through holes inside the LDPE matrix. As the diffusion rate of cupric ions in the LDPE matrix is lower than that in solution, the rate of cupric ion release from the nano- $\mathrm{Cu} /$ LDPE IUD is considered a stable slow-release process. This type of controlled cupric ion-release system can avoid the wide spectrum of effects produced by overexposure.

In recent years, the public has increasingly expressed concerns about the effects of nanoparticles on health. Nanoparticles have a large surface area per mass, which directly 
Table 4 Clinical biochemistry values of male rats $(\mathbf{A})$ and female rats (B) in subchronic toxicity study

\begin{tabular}{|c|c|c|}
\hline \multicolumn{3}{|l|}{ A } \\
\hline Parameters & $\begin{array}{l}\text { Nano-Cu/LDPE } \\
\text { group }(n=5)\end{array}$ & $\begin{array}{l}\text { Control } \\
\text { group }(n=5)\end{array}$ \\
\hline ALT (U/L) & $47.6 \pm 3.58$ & $50.5 \pm 6.20$ \\
\hline TP $(g / L)$ & $80.3 \pm 3.54$ & $81.3 \pm 2.61$ \\
\hline ALB (g/L) & $30.4 \pm 1.06$ & $29.1 \pm 1.18$ \\
\hline TBIL $(\mu \mathrm{mol} / \mathrm{L})$ & $1.48 \pm 0.08$ & $1.36 \pm 0.21$ \\
\hline AST (U/L) & $195.6 \pm 40.5$ & $163.8 \pm 11.0$ \\
\hline $\mathrm{T}-\mathrm{CHO}(\mathrm{mmol} / \mathrm{L})$ & $1.56 \pm 0.32$ & $1.58 \pm 0.08$ \\
\hline BUN (mmol/L) & $6.06 \pm 0.63$ & $6.10 \pm 0.56$ \\
\hline $\mathrm{Cr}(\mu \mathrm{mol} / \mathrm{L})$ & $23.8 \pm 1.53$ & $23.62 \pm 1.49$ \\
\hline GLU (mmol/L) & $5.08 \pm 0.23$ & $5.76 \pm 0.44$ \\
\hline $\mathrm{Na}(\mathrm{mmol} / \mathrm{L})$ & $|45.| \pm \mid .5$ & $|44.8 \pm| .3$ \\
\hline $\mathrm{K}(\mathrm{mmol} / \mathrm{L})$ & $6.16 \pm 0.29$ & $6.28 \pm 0.45$ \\
\hline $\mathrm{Cl}(\mathrm{mmol} / \mathrm{L})$ & $106.9 \pm 0.9$ & $106.5 \pm 1.4$ \\
\hline \multicolumn{3}{|l|}{ B } \\
\hline Parameters & $\begin{array}{l}\text { Nano-Cu/LDPE } \\
\text { group }(n=5)\end{array}$ & $\begin{array}{l}\text { Control } \\
\text { group }(n=5)\end{array}$ \\
\hline ALT (U/L) & $44.8 \pm 6.57$ & $44.4 \pm 2.30$ \\
\hline $\mathrm{TP}(\mathrm{g} / \mathrm{L})$ & $70.2 \pm 3.97$ & $74.4 \pm 4.03$ \\
\hline ALB (g/L) & $34.0 \pm 1.68$ & $31.9 \pm 1.92$ \\
\hline TBIL $(\mu \mathrm{mol} / \mathrm{L})$ & $1.26 \pm 0.23$ & $1.28 \pm 0.18$ \\
\hline AST (U/L) & $166.2 \pm 22.7$ & $177.7 \pm 29.3$ \\
\hline $\mathrm{T}-\mathrm{CHO}$ (mmol/L) & $1.48 \pm 0.13$ & $1.24 \pm 0.17$ \\
\hline BUN (mmol/L) & $6.32 \pm 1.04$ & $6.48 \pm 0.97$ \\
\hline $\mathrm{Cr}(\mu \mathrm{mol} / \mathrm{L})$ & $24.48 \pm 2.27$ & $23.32 \pm 2.10$ \\
\hline GLU (mmol/L) & $5.76 \pm 0.84$ & $5.22 \pm 0.85$ \\
\hline $\mathrm{Na}(\mathrm{mmol} / \mathrm{L})$ & $145.3 \pm 0.7$ & $144.2 \pm 2.6$ \\
\hline $\mathrm{K}(\mathrm{mmol} / \mathrm{L})$ & $5.66 \pm 0.80$ & $5.66 \pm 0.62$ \\
\hline $\mathrm{Cl}(\mathrm{mmol} / \mathrm{L})$ & $106.8 \pm 0.9$ & $106.5 \pm 0.7$ \\
\hline
\end{tabular}

Note: Values expressed as mean $\pm S D$.

Abbreviations: ALB, albumin; ALT, alanine aminotransferase; AST, aspartate aminotransferase; BUN, blood urea nitrogen; $\mathrm{Cl}$, chloride; $\mathrm{Cr}$, creatinine; $\mathrm{Cu} / \mathrm{LDPE}$, copper/low-density polyethylene nanocomposite; GLU, glucose; K, potassium; $\mathrm{Na}$, sodium; TBIL, total bilirubin; T-CHO, total cholesterol; TP, total protein.

increases the risk of toxicity via reactive surface atoms and molecules. ${ }^{33}$ The mechanisms of copper nanoparticlemediated toxicity involve the generation of ROS, which can damage most biologic molecules, including DNA, protein, and lipids, and consequently damage cellular membranes and various organelles. ${ }^{34,35}$ Moreover, a study in which mice were acutely exposed to copper nanoparticles or microparticles found that only the former induced severe impairment of the kidney, liver, and spleen. ${ }^{36} \mathrm{~A}$ further study revealed a strong correlation of the size/specific surface area of copper nanoparticles with toxicity, and a study of mice exposed to copper nanoparticles observed metabolic alkalosis and copper accumulation in the kidneys. ${ }^{37}$ Yet another study observed overt toxicity in male Wistar rats that had been orally administered $200 \mathrm{mg} / \mathrm{kg}$ of copper nanoparticles daily for 5 days. Here,
Table 5 Relative organ weights of male rats $(\mathbf{A})$ and female rats (B) in subchronic toxicity study

\begin{tabular}{lll}
\hline A & Nano-Cu/LDPE & Control \\
\hline Parameters & $0.42 I \pm 0.057$ & group (n=5) \\
\hline Brain (\%) & $0.305 \pm 0.047$ & $0.457 \pm 0.042$ \\
Heart (\%) & $0.154 \pm 0.028$ & $0.350 \pm 0.039$ \\
Thymus (\%) & $2.537 \pm 0.362$ & $0.164 \pm 0.029$ \\
Liver (\%) & $0.249 \pm 0.041$ & $3.038 \pm 0.05$ I \\
Spleen (\%) & $0.584 \pm 0.044$ & $0.320 \pm 0.048$ \\
Kidney (\%) & $0.013 \pm 0.001$ & $0.618 \pm 0.048$ \\
Adrenal gland (\%) & $0.733 \pm 0.092$ & $0.013 \pm 0.002$ \\
Testes (\%) & & $0.850 \pm 0.080$ \\
\hline B & $\mathbf{N a n o - C u / L D P E}$ & $\mathbf{C o n t r o l}$ \\
\hline Parameters & group (n=5) & group (n=5) \\
\hline Brain (\%) & $0.475 \pm 0.043$ & $0.489 \pm 0.058$ \\
Heart (\%) & $0.300 \pm 0.030$ & $0.31 I \pm 0.032$ \\
Thymus (\%) & $0.163 \pm 0.050$ & $0.162 \pm 0.012$ \\
Liver (\%) & $2.691 \pm 0.629$ & $2.782 \pm 0.445$ \\
Spleen (\%) & $0.304 \pm 0.054$ & $0.327 \pm 0.030$ \\
Kidney (\%) & $0.560 \pm 0.022$ & $0.552 \pm 0.065$ \\
Adrenal gland (\%) & $0.025 \pm 0.001$ & $0.022 \pm 0.005$ \\
Ovaries (\%) & $0.065 \pm 0.006$ & $0.642 \pm 0.004$ \\
Uterus (\%) & $0.177 \pm 0.010$ & $0.204 \pm 0.013$ \\
\hline Note: Values expressed as mean \pm SD. & \\
Abbreviation: nano-Cu/LDPE, copper/low-density polyethylene nanocomposite.
\end{tabular}

the kidney, a target organ, contained widespread necrosis of the renal proximal tubule cells. In a previous study, we showed that exposure to copper nanoparticles for 14 days can cause ovarian injury in rats. These findings only imply that exposure to copper nanoparticles should be a matter of concern. ${ }^{38}$ Overall, caution should be exercised when applying copper nanoparticles in various areas.

The toxicity associated with copper nanoparticles has been verified using conventional toxicologic parameters, including body weight, clinical chemistry, and histopathology.$^{39}$ However, the results of the present systemic toxicity analysis found no symptoms of toxicity in any animal exposed to the nano-Cu/LDPE IUD. A histopathologic examination of the liver, spleen, kidneys, and ovaries at the end of the study revealed normal architecture, with no indication of morphologic disturbances. The unique characteristics of the nano-Cu/LDPE IUD might explain this lack of any systemic reaction. As shown in our previous work, the nano- $\mathrm{Cu} / \mathrm{LDPE}$ composite is a simple hybrid of copper nanoparticles and pure LDPE wherein almost all of the copper nanoparticles are enveloped by LDPE. After the copper nanoparticles within the nanocomposite are corroded in the uterine solution, LDPE remains the outer layer of the 

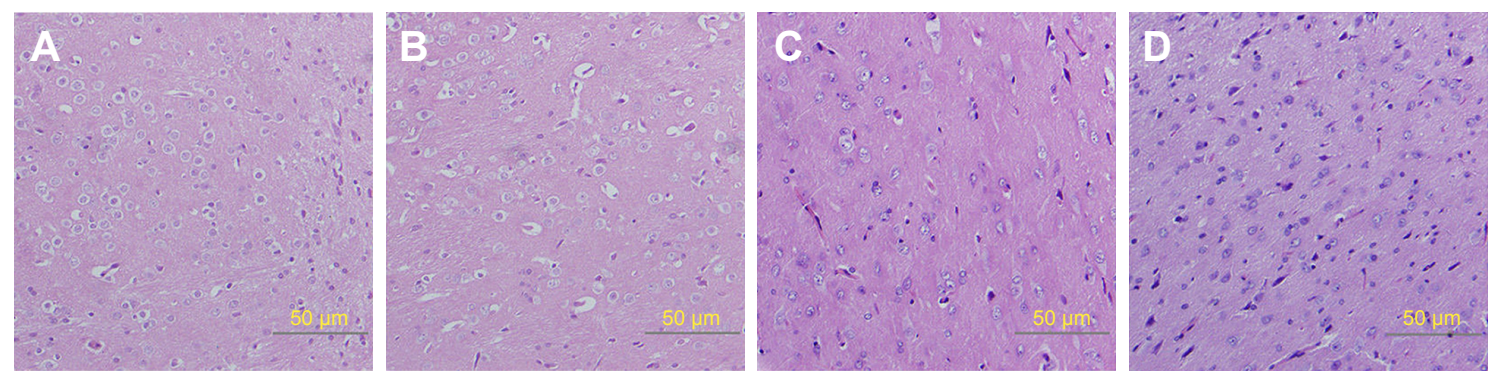

\section{Brain}
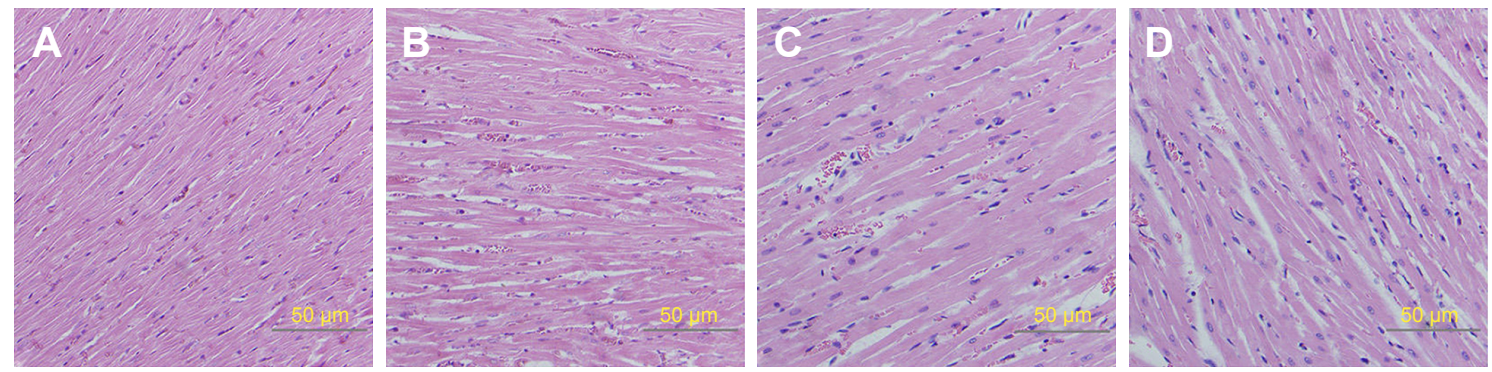

\section{Heart}
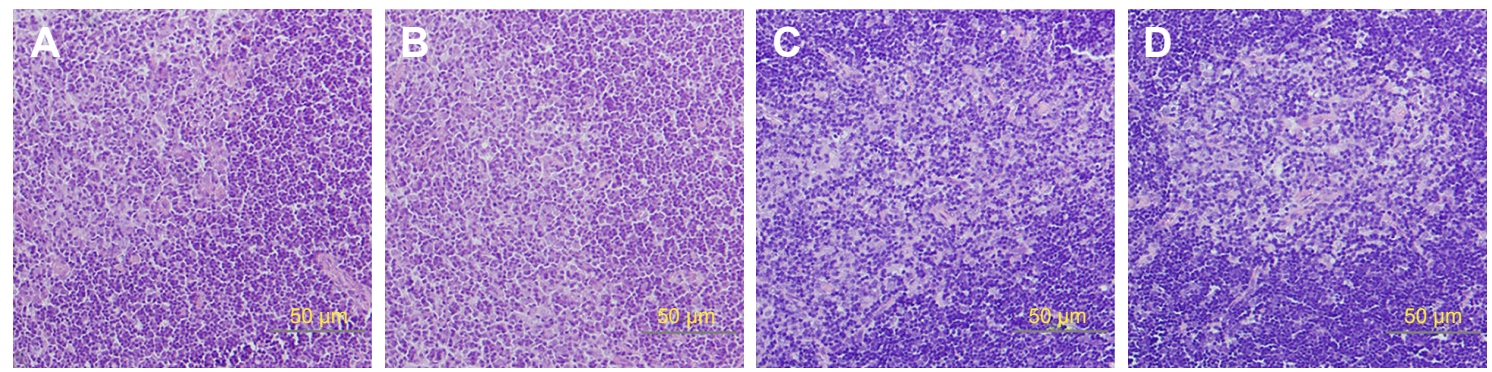

Thymus

Figure 6 Histologic sections of brain, heart, and thymus.

Notes: (A) Male rats of nano-Cu/LDPE group. (B) Male rats of control group. (C) Female rats of nano-Cu/LDPE group. (D) Female rats of control group. No statistically significant changes were detected in any groups.

Abbreviation: Cu/LDPE, copper/low-density polyethylene nanocomposite.
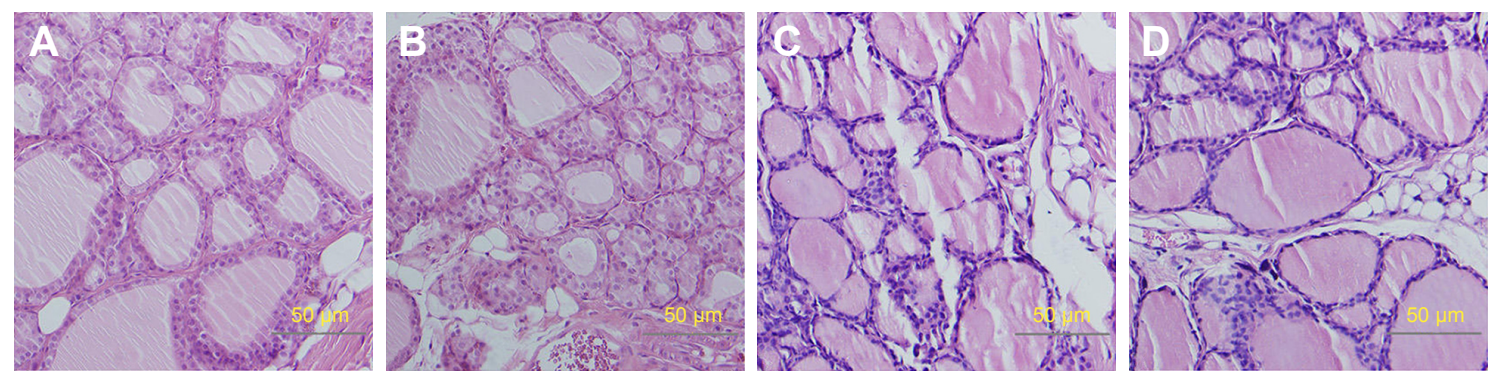

\section{Thyroid}
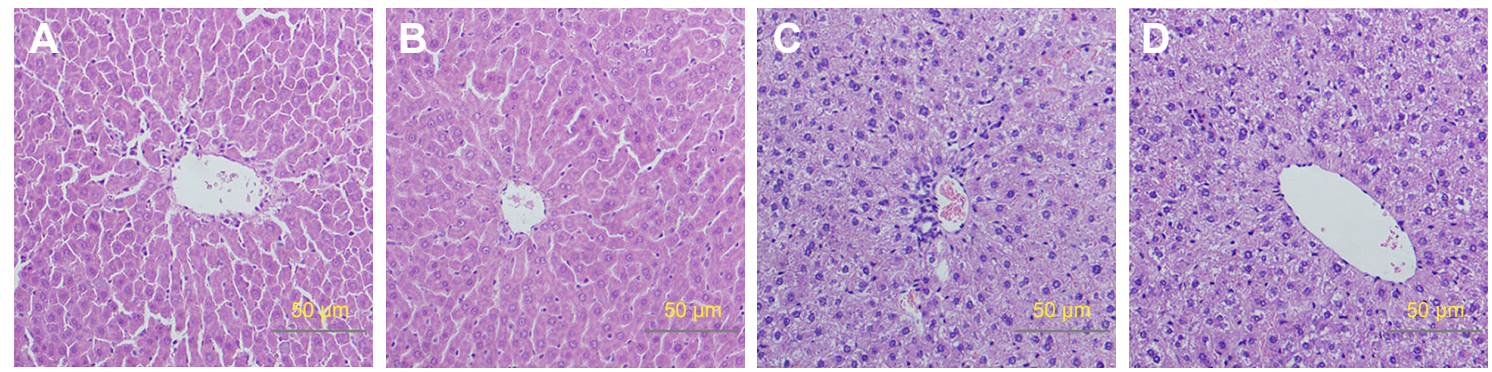

\section{Liver}



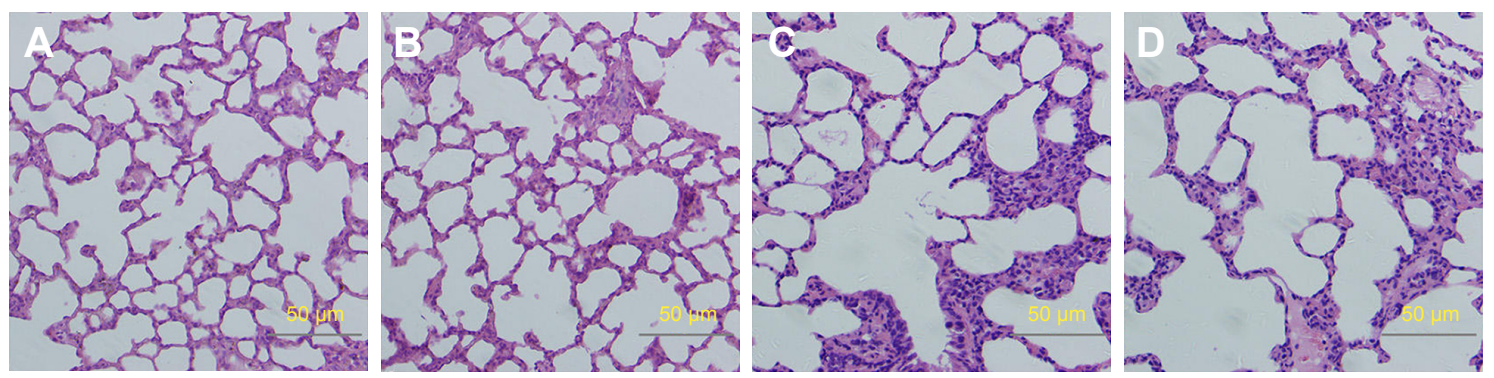

\section{Lung}

Figure 7 Histologic sections of thyroid, liver, and lung.

Notes: (A) Male rats of nano-Cu/LDPE group. (B) Male rats of control group. (C) Female rats of nano-Cu/LDPE group. (D) Female rats of control group. No abnormalities were detected in any groups.

Abbreviation: Cu/LDPE, copper/low-density polyethylene nanocomposite.

nanocomposite. ${ }^{17,40}$ In addition, the results from a cytotoxicity assay in which the membranes of L929 mouse fibroblasts were cultured with nano-Cu/LDPE IUD extracts for 5 days are integral. The morphologies of these L929 mouse fibroblasts were near normal according to light microscopy and scanning electron microscopy evaluations. ${ }^{18}$ Therefore, the copper nanoparticles appear to have little effect on the surface condition of the nano-Cu/LDPE IUD.

In conclusion, the results presented in this study indicate the absence of systemic toxicity in response to acute and
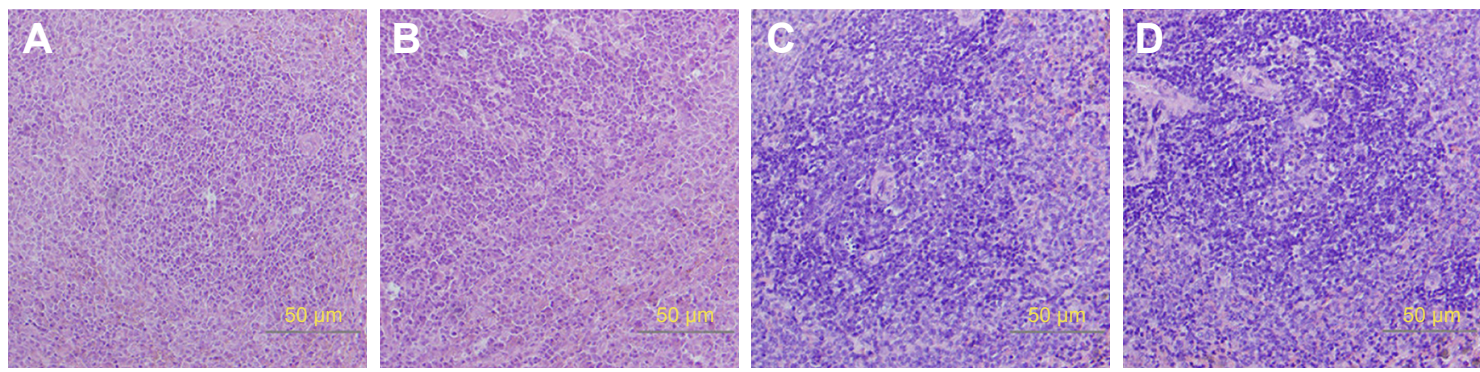

\section{Spleen}
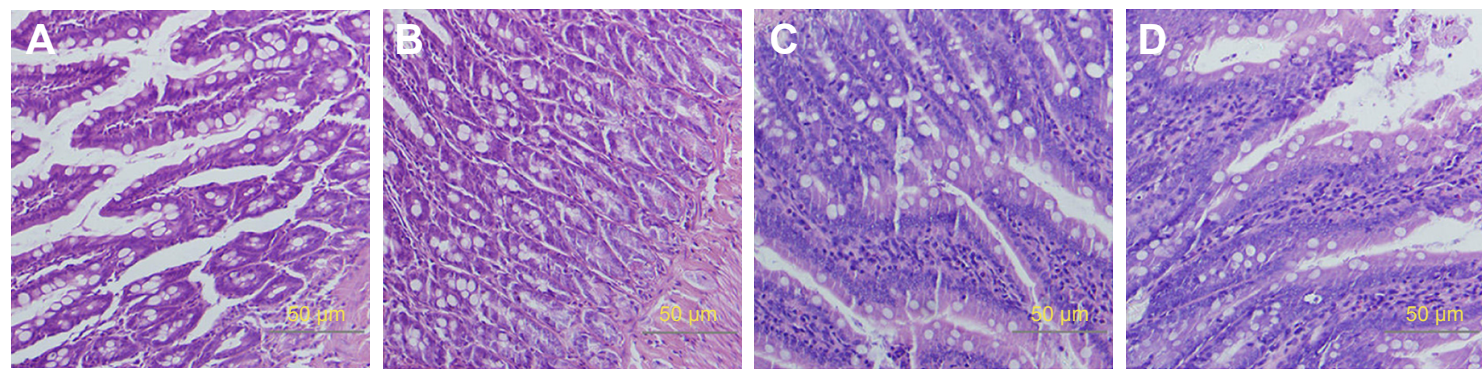

Intestine
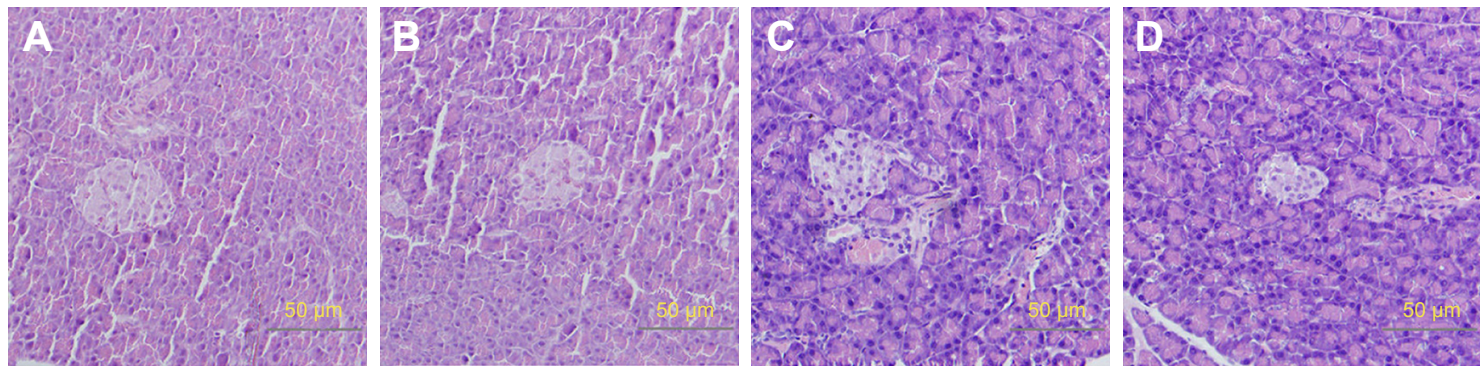

\section{Pancreas}

Figure 8 Histologic sections of spleen, intestine, and pancreas.

Notes: (A) Male rats of nano-Cu/LDPE group. (B) Male rats of control group. (C) Female rats of nano-Cu/LDPE group. (D) Female rats of control group. No abnormalities were detected in any groups.

Abbreviation: Cu/LDPE, copper/low-density polyethylene nanocomposite. 

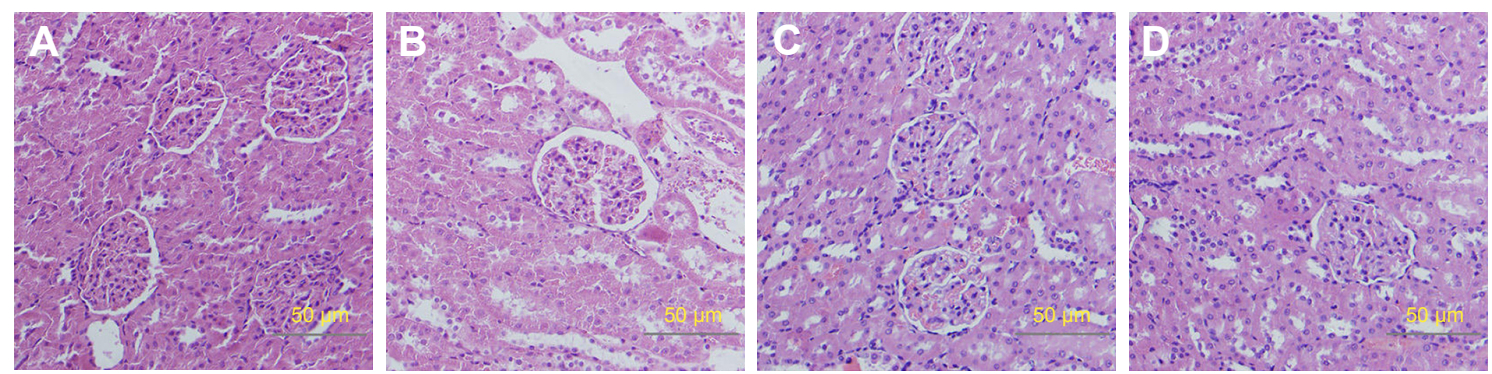

\section{Kidney}
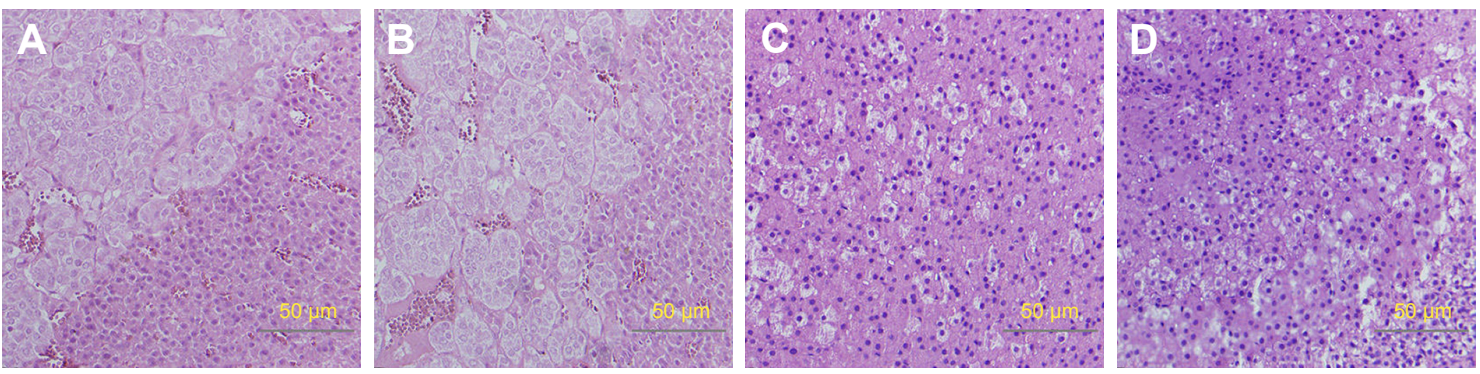

\section{Adrenal gland}

Figure 9 Histologic sections of kidney and adrenal gland.

Notes: (A) Male rats of nano-Cu/LDPE group. (B) Male rats of control group. (C) Female rats of nano-Cu/LDPE group. (D) Female rats of control group. No abnormalities were detected in any groups.

Abbreviation: Cu/LDPE, copper/low-density polyethylene nanocomposite.

subchronic exposure to the nano- $\mathrm{Cu} / \mathrm{LDPE}$ IUD under the test conditions. These findings suggest that an IUD comprising this novel material would be safe and feasible for future applications as a contraceptive device. However, further preclinical toxicologic studies must be conducted according to the ISO-recommended protocols for evaluating the toxicity of a medical device. Additional studies of the reproductive toxicity and genotoxicity associated with the nano-Cu/LDPE IUD are already in progress to assess the ultimate suitability of this device for end-use human applications.
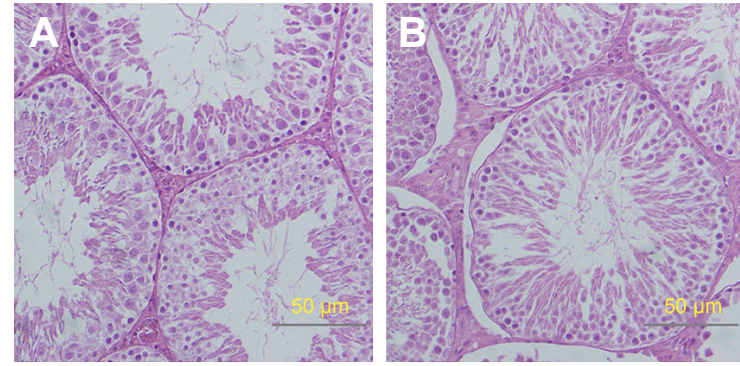

Testis

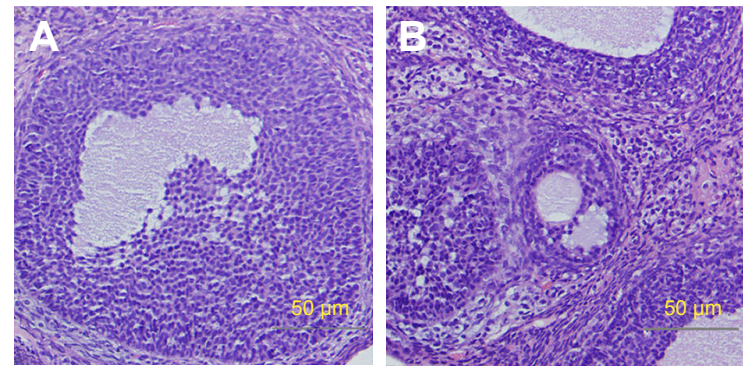

Ovaries

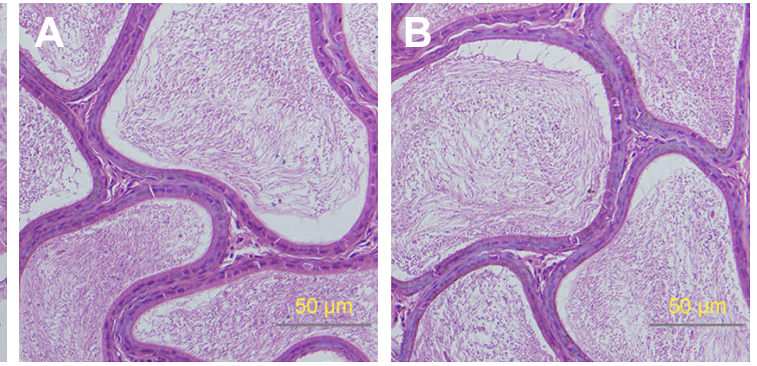

Epididymis

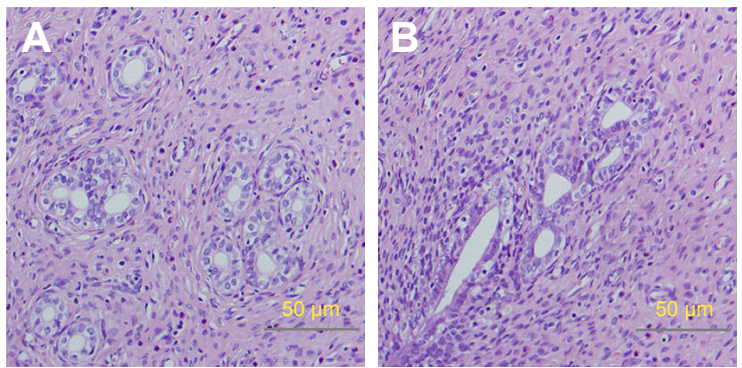

Uterus

Figure 10 Histologic sections of testis, epididymis, ovaries, and uterus.

Notes: (A) The nano-Cu/LDPE group. (B) The control group. No abnormalities were detected in any groups.

Abbreviation: Cu/LDPE, copper/low-density polyethylene nanocomposite. 


\section{Acknowledgments}

This work was supported by the National Natural Science Foundation of China (grant no 81671507) and the National Key Research and Development Program (grant no 2016YFC1000903).

\section{Disclosure}

The authors report no conflicts of interest in this work.

\section{References}

1. Sivin I, Batár I. State-of-the-art of non-hormonal methods of contraception: III. Intrauterine devices. Eur J Contracept Reprod Health Care. 2010;15(2):96-112.

2. Stanford JB, Mikolajczyk RT. Mechanisms of action of intrauterine devices: update and estimation of postfertilization effects. Am J Obstet Gynecol. 2002;187(6):1699-1708.

3. Wang D, Altmann DR. Socio-demographic determinants of intrauterine device use and failure in China. Hum Reprod. 2002;17(5):1226-1232.

4. Hubacher D, Lara-Ricalde R, Taylor DJ, Guerra-Infante F, GuzmánRodríguez R. Use of copper intrauterine devices and the risk of tubal infertility among nulligravid women. $N$ Engl J Med. 2001;345(8):561-567.

5. Sivin I. Utility and drawbacks of continuous use of a copper T IUD for 20 years. Contraception. 2007;75(6 Suppl):S70-S75.

6. Arancibia V, Peña C, Allen HE, Lagos G. Characterization of copper in uterine fluids of patients who use the copper T-380A intrauterine device. Clin Chim Acta. 2003;332(1-2):69-78.

7. Yu J, Li J, Li HG, Li JX, Xie CS, Zhu CH. Comparative study on contraceptive efficacy and clinical performance of the copper/lowdensity polyethylene nanocomposite IUD and the copper T220C IUD. Contraception. 2008;78(4):319-323.

8. Hu LX, Wang H, Rao M, et al. Alterations in the endometrium of rats, rabbits, and Macaca mulatta that received an implantation of copper/low-density polyethylene nanocomposite. Int $J$ Nanomed. 2014;9:1127-1138.

9. Cai S, Xia X, Xie C. Research on $\mathrm{Cu}^{2+}$ transformations of $\mathrm{Cu}$ and its oxides particles with different sizes in the simulated uterine solution. Corros Sci. 2005;47(4):1039-1047.

10. Xia X, Xie C, Cai S, Yang Z, Yang X. Corrosion characteristics of copper microparticles and copper nanoparticles in distilled water. Corros Sci. 2006;48(12):3924-3932.

11. Xia X, Tang Y, Xie C, Wang Y, Cai S, Zhu C. An approach to give prospective life-span of the copper/low-density-polyethylene nanocomposite intrauterine device. J Mater Sci Mater Med. 2011;22(7):1773-1781.

12. Tang Y, Xia X, Wang Y, Xie C. Study on the mechanical properties of $\mathrm{Cu} /$ LDPE composite IUDs. Contraception. 2011;83(3):255-262.

13. Liu HF, Liu ZL, Xie CS, Yu J, Zhu CH. The antifertility effectiveness of copper/low-density polyethylene nanocomposite and its influence on the endometrial environment in rats. Contraception. 2007;75(2): 157-161.

14. Di HH, Zhu CH, Xie CS, Xia XP, Zhen B, Liu ZL. Influence of nano-Cu/LDPE-IUD on ultrastructure of rabbit endometrium. Reprod Contracept. 2006;26(10):584-588.

15. Zhen B, Zhu CH, Xie CS, et al. Impact of nano-Cu/LDPE-IUD on the level of t-PA, PAF, $\mathrm{PGE}_{2}$ in the uterine fluid of Macaca mulatta. Reprod Contracept. 2006;26(8):467-471.

16. Li J, Liu Z, Li S, et al. Correlative investigation of copper/low-density polyethylene nanocomposite on the endometrial angiogenesis in rats. Front Med China. 2007;1(4):1-4.

17. Xia X, Xie C, Zhu C, Cai S, Yang X. Effect of implanted Cu/low-density polyethylene nanocomposite on the morphology of endometrium in the mouse. Fertil Steril. 2007;88(2):472-478.

18. Hu LX, He J, Hou L, et al. Biological evaluation of the copper/lowdensity polyethylene nanocomposite intrauterine device. PLoS One. 2013;8(9):e74128.
19. International Organization for Standardization. ISO 10993-11. Biological evaluation of medical devices - part 11: Tests for systemic toxicity; 2006. Available from: https://www.iso.org/standard/35977. html. Accessed August 15, 2018.

20. International Organization for Standardization. ISO 10993-12. Biological evaluation of medical devices - part 12: Sample preparation and reference materials; 2007. Available from: https://www.iso.org/ standard/53468.html. Accessed August 15, 2018.

21. Patchen L, Berggren EK. Use of the copper T380A intrauterine device by adolescent mothers: continuation and method failure. $J$ Pediatr Adolesc Gynecol. 2011;24(2):71-73.

22. Kaislasuo J, Suhonen S, Gissler M, Lahteenmaki P, Heikinheimo O. Uterine perforation caused by intrauterine devices: clinical course and treatment. Hum Reprod. 2013;28(6):1546-1551.

23. Alvarez F, Grillo C, Schilardi P, et al. Decrease in cytotoxicity of copperbased intrauterine devices (IUD) pretreated with 6-mercaptopurine and pterin as biocompatible corrosion inhibitors. ACS Appl Mater Interfaces. 2013;5(2):249-255.

24. Letelier ME, Lepe AM, Faúndez M, et al. Possible mechanisms underlying copper-induced damage in biological membranes leading to cellular toxicity. Chem Biol Interact. 2005;151(2):71-82.

25. Moriwaki H, Osborne MR, Phillips DH. Effects of mixing metal ions on oxidative DNA damage mediated by a Fenton-type reduction. Toxicol In Vitro. 2008;22(1):36-44.

26. Araya R, Gómez-Mora H, Vera R, Bastidas JM. Human spermatozoa motility analysis in a Ringer's solution containing cupric ions. Contraception. 2003;67(2):161-163.

27. Beigzadeh Ghelejlu S, Esmaiili M, Almasi H. Characterization of chitosan-nanoclay bionanocomposite active films containing milk thistle extract. Int J Biol Macromol. 2016;86:613-621.

28. Liu F, Hu CY, Zhao Q, Shi YJ, Zhong HN. Migration of copper from nanocopper/LDPE composite films. Food Addit Contam Part A Chem Anal Control Expo Risk Assess. 2016;33(11):1741-1749.

29. Dealba-Montero I, Guajardo-Pacheco J, Morales-Sánchez E, et al. Antimicrobial properties of copper nanoparticles and amino acid chelated copper nanoparticles produced by using a soya extract. Bioinorg Chem Appl. 2017;2017(2):Article ID 1064918, 6pp.

30. Ashfaq M, Verma N, Khan S. Copper/zinc bimetal nanoparticlesdispersed carbon nanofibers: a novel potential antibiotic material. Mater Sci Eng C Mater Biol Appl. 2016;59:938-947.

31. Grillo CA, Reigosa MA, de Mele MA. Does over-exposure to copper ions released from metallic copper induce cytotoxic and genotoxic effects on mammalian cells? Contraception. 2010;81(4):343-349.

32. Cai S, Xia X, Xie C. Corrosion behavior of copper/LDPE nanocomposites in simulated uterine solution. Biomaterials. 2005;26(15):2671-2676.

33. Nel A, Xia T, Madler L, Li N. Toxic potential of materials at the nanolevel. Science. 2006;311(5761):622-627.

34. Kaiser J-P, Zuin S, Wick P. Is nanotechnology revolutionizing the paint and lacquer industry? A critical opinion. Sci Total Environ. 2013;442: 282-289.

35. Zheng JL, Yuan SS, Wu CW, Lv ZM. Acute exposure to waterborne cadmium induced oxidative stress and immunotoxicity in the brain, ovary and liver of zebrafish (Danio rerio). Aquat Toxicol. 2016;180:36-44.

36. Chen Z, Meng H, Xing G, et al. Acute toxicological effects of copper nanoparticles in vivo. Toxicol Lett. 2006;163(2):109-120.

37. Meng H, Chen Z, Xing G, et al. Ultrahigh reactivity provokes nanotoxicity: explanation of oral toxicity of nano-copper particles. Toxicol Lett. 2007;175(1-3):102-110.

38. Yang J, Hu S, Rao M, et al. Copper nanoparticle-induced ovarian injury, follicular atresia, apoptosis, and gene expression alterations in female rats. Int J Nanomed. 2017;12:5959-5971.

39. Liao M, Liu H. Gene expression profiling of nephrotoxicity from copper nanoparticles in rats after repeated oral administration. Environ Toxicol Pharmacol. 2012;34(1):67-80.

40. Xia X, Cai S, Xie C. Preparation, structure and thermal stability of Cu/LDPE nanocomposites. Mater Chem Phys. 2006;95(1):122-129. 


\section{Publish your work in this journal}

The International Journal of Nanomedicine is an international, peerreviewed journal focusing on the application of nanotechnology in diagnostics, therapeutics, and drug delivery systems throughout the biomedical field. This journal is indexed on PubMed Central, MedLine, CAS, SciSearch $\AA$, Current Contents $\AA /$ Clinical Medicine,

Journal Citation Reports/Science Edition, EMBase, Scopus and the Elsevier Bibliographic databases. The manuscript management system is completely online and includes a very quick and fair peer-review system, which is all easy to use. Visit http://www.dovepress.com/ testimonials.php to read real quotes from published authors.

Submit your manuscript here: http://www.dovepress.com/international-journal-of-nanomedicine-journal 